\title{
Da Pobreza Química à Sustentabilidade e Química Verde
}

\author{
AdélIo A. S. C. Machado*
}

\begin{abstract}
A partir de uma análise de dados estatísticos sobre a produção da Indústria Química de alguns países, bem como à escala mundial, introduz-se o conceito de pobreza química, uma componente da pobreza tecnológica presumivelmente tão importante como a pobreza energética. Como a pobreza química afecta uma parte significativa da população mundial, a sua eliminação no âmbito do Desenvolvimento Sustentável requer o aumento da produção e utilização de produtos químicos à escala global - e pressiona o desenvolvimento da Química Verde, essencial para que esse aumento seja implementado de forma benigna para o ambiente e saúde humana, conforme exige a Sustentabilidade.
\end{abstract}

Este artigo teve duas fontes inspiradoras de natureza muito diferente: por um lado, o conceito de pobreza energética, que se refere à situação de quase um terço da população mundial não ter acesso a serviços de fornecimento de energia (para uma visão global do alcance actual deste problema ver [1]) ${ }^{1}$; por outro, alguns dados estatísticos sobre a actividade da Indústria Química e a produção de produtos químicos nos EUA, a nível mundial e em países de nível de riqueza diferentes, divulgados pelo American Chemical Council (ACC ou $\mathrm{AC}_{2}$ ), a associação das empresas da Indústria Química daquele país [2].²

O artigo tem os seguintes objectivos: primeiro, discutir brevemente a importância que a Indústria Química tem para o funcionamento da civilização industrial em vigor nos países avançados - à qual aspiram também as populações dos países em desenvolvimento - e para os respectivos economia e emprego; segundo, fazer sentir que há diferenças marcadas entre a produção e consumo de produtos químicos entre os países avançados e os países em desenvolvimento - o que conduz ao conceito de pobreza química; terceiro, como consequência dos anteriores, chamar a atenção para o facto de o Desenvolvimento Sustentável, quando prescreve a eliminação

\footnotetext{
* Departamento de Química da Faculdade de Ciências da Universidade do Porto, R. Campo Alegre, 687, amachado@fc.up.pt
}

das desigualdades entre os países pouco desenvolvidos e os países afluentes, com respeito pela conservação do ambiente e biosfera, implicar quer o crescimento da produção de químicos pela Química Industrial, quer a necessidade de inovar este campo de actividade da tecnosfera no sentido de o compatibilizar com a ecosfera - o que exige uma prática crescente e voluntariosa de Química Verde.

\section{IMPORTÂNCIA DOS PRODUTOS QUÍMI- COS NA VIDA DIÁRIA DOS CIDADÃOS}

Os produtos químicos são omnipresentes na vida diária das populações dos países desenvolvidos, como tal ou incorporados na maior parte dos bens que são usados, real ou virtualmente $^{3}$ - um facto tão trivial que é frequentemente esquecido pelas pessoas comuns e mesmo pelos profissionais da química: os produtos químicos acabam por ter um "estatuto de clandestinos", só sendo lembrados quando causam problemas.

Na Tabela 1 (inspirada em [3]) ilustra-se esta situação, enumerando bens com que os habitantes dos países afluentes lidam todos os dias, quando estão em casa, ou vão às compras, ou saem nos tempos livres, etc. - esses bens ou são produtos químicos (a maior parte deles, produtos formula$\operatorname{dos}^{4}$ ), ou objectos em cujo fabrico ou produção foram adicionados, incorporados ou utilizados produtos químicos, em maior ou menor extensão. ${ }^{5} \mathrm{~A}$ grande maioria dos bens, materiais, utensílios, etc., que os habitantes dos países afluentes usam diariamente, proporcionando comodidade, conforto, etc., enfim, qualidade de vida, não existiriam, pelo menos na sua forma actual, se a Indústria Química não produzisse uma grande variedade de produtos químicos.

Se o leitor ainda não está convencido da extrema importância para a civilização industrial dos produtos químicos, olhe em volta e procure encontrar um objecto ou qualquer coisa que tenha sido feita sem a intervenção, óbvia ou não, de produtos químicos. Se nada encontrar no sítio onde está, não desespere - e, sempre que mudar de sítio, continue a procurar. Eventualmente, quando chegar a noite, se estiver luar, poderá ver a Lua, que está ainda isenta de produtos químicos - só que não é algo que tenha sido fabricado pelos humanos. ${ }^{6}$

Em suma, os habitantes dos países afluentes conseguem ter qualidade de vida graças a uma utilização intensiva dos produtos fabricados pela Indústria Química em grande número e, em muitos casos, em tonelagens elevadas, e que são utilizados para os mais diversos fins, a nível pessoal ou colectivo. A discussão a seguir mostra o importante papel económico-social daquela indústria nos países avançados e analisa como a produção de químicos está relacionada com o nível de riqueza - que, como se sabe, é um dos principais factores que proporciona qualidade de vida. 
Tabela 1 Bens de consumo feitos, conservados, embalados, etc., com químicos*

\begin{tabular}{|l|l|}
\hline \multicolumn{2}{|c|}{ Casa } \\
\hline Quarto & Lençóis, almofadas, mobílias, candeeiros, roupas, etc. \\
\hline Quarto de banho & $\begin{array}{l}\text { Sabonete, pasta de dentes, creme de barbear, desodorizante, cosméticos, } \\
\text { toalhas, remédios, etc. }\end{array}$ \\
\hline Cozinha & $\begin{array}{l}\text { Fogão, frigorífico, máquinas de lavar, tachos e utensílios, alimentos, detergentes, } \\
\text { etc. }\end{array}$ \\
\hline Garagem & Carro, bicicleta, escada, detergente, polimento, tintas, solventes, etc. \\
\hline \multicolumn{1}{|c|}{ Supermercado } \\
\hline
\end{tabular}

\begin{tabular}{|c|c|}
\hline Alimentos & Leite e bebidas derivadas, pão, sumos, queijos, iogurtes, carne, etc. \\
\hline Limpeza & $\begin{array}{l}\text { Sabões e detergentes (sólidos e líquidos), lixívias, tira-nódoas, ceras (soalho e } \\
\text { mobília, etc.), etc. }\end{array}$ \\
\hline Higiene pessoal & $\begin{array}{l}\text { Produtos dentários (pasta, líquidos para bochechar), produtos de barbear (gilete, } \\
\text { creme, loções), sabonetes e champôs, desodorizantes, etc. }\end{array}$ \\
\hline Automóvel & Pneus, lubrificantes e aditivos, anticongelantes, ceras de polimento, etc. \\
\hline
\end{tabular}

\begin{tabular}{|l|l|}
\hline Roupas & Vestidos, fatos, camisas, malhas, roupa interior, etc. \\
\hline Couros & Sapatos, carteiras, cintos, graxas, etc. \\
\hline Brinquedos & Carros, bonecas, jogos, peças de lego, etc. \\
\hline Utensílios para casa & Colheres, facas, tachos, abre-latas, etc. \\
\hline Farmácia & Analgésicos, antiácidos, xaropes para a tosse, líquidos para os olhos, etc. \\
\hline & \multicolumn{1}{|c|}{ Praia } \\
\hline
\end{tabular}

\begin{tabular}{|l|l|}
\hline Água & Pranchas de surf, barcos, bóias, óculos de natação, etc. \\
\hline Areia & Guarda-sol, toalhas, colchão, bolas, etc. \\
\hline Bar & Sanduíches, bolos, bebidas (cocacola, cerveja, etc.), gelados, etc. \\
\hline Banho & Protectores solares, loções, fatos de banho, T-shirts, chapéus, óculos de sol, etc \\
\hline Pesca & Cana, linhas, anzóis, etc. \\
\hline
\end{tabular}

*) Inspirada em [3]

\section{Alcance económico-social DA INDÚSTRIA Química}

Em 2005, o ACC encomendou a uma consultora económica estudos que permitissem quantificar, mais incisivamente do que as estatísticas de venda, o alcance para a economia da actividade da Indústria Química nos EUA - por outros palavras, em que extensão o uso de produtos químicos atingia o estilo de vida da população, as outras actividades industriais, incluindo os serviços, etc., enfim, a sociedade em globo, e contribuía directa e indirectamente para o PIB e o emprego. O objectivo final era mostrar ao público, de forma facilmente compre- ensível, o papel essencial da Indústria Química na economia do país - algo que a indústria sabe muito bem, mas que o público ignora ou, pelo menos, a que não presta atenção. Os resultados obtidos, muito elucidativos da omnipresença dos produtos químicos na actividade económico-social dos EUA e, por semelhança, dos outros países avançados, são sumariados a seguir.

Os indicadores ChemFactor. Os estudos envolveram a definição e cálculo de um indicador económico, o ChemFactor - um indicador de toque, ${ }^{7}$ cujo objectivo é aferir e mostrar até que ponto a Indústria Química tem efeitos ("toca") nas restantes actividades do país através do uso de produtos químicos [4]. Esse indicador pode ser calculado para as diversas indústrias e serviços, classes de produtos ou o consumo (ver a Tabela 2). ${ }^{8}$ Por exemplo, o ChemFactor para uma indústria é a percentagem do total de compras por essa indústria que são produtos químicos, materiais constituídos por produtos químicos ou seus derivados fabricados pela Indústria Química; na Tabela 2 (parte 1) apresentam-se exemplos de valores para diversos sectores industriais e tipos de produtos. Por exemplo, para o fabrico de tintas de impressão, o indicador tem o valor 100 - todos os materiais usados no fabrico provêm da Indústria Química; para o fabrico de pranchas de madeira aglomerada, o valor do indicador é $31-31 \%$, em valor, dos materiais usados são produtos químicos, as resinas sintéticas usadas na aglutinação dos pedaços de madeira e outros.

Semelhantemente, podem-se calcular valores para classes de produtos com funções especializadas - por exemplo, a Tabela 2 (parte 2) inclui valores para diferentes produtos usados em embalagens. A embalagem é quase sempre algo imprescindível na venda de qualquer objecto ou bem e a quantidade de químicos gastos nela é frequentemente dominante. A tabela mostra, por exemplo, que os valores do ChemFactor para embalagens plásticas são da ordem de 70-80: Materiais plásticos para embalagem, 77; Garrafas de plástico, 74. O valor 77, à primeira vista anormalmente baixo para materiais plásticos, que são essencialmente produtos químicos, tem como provável explicação a elevada voracidade energética da Química Industrial Orgânica, nomeadamente a dos produtos de base dos plásticos (o decréscimo ligeiro de 77 para 74 para as garrafas corresponde à manufactura mecânica destas a partir do material plástico, um processo relativamente simples, que consome relativamente pouca energia quando comparado com os que o precedem na cadeia de valor daquele produto final).

O ChemFactor calculado para as diversas facetas do consumo mede o grau de contribuição dos produtos químicos para os bens de consumo. A Tabela 2 (parte 3) mostra que muitos dos bens que permitem qualidade 
de vida às pessoas incorporam uma grande ou razoável contribuição relativa de produtos químicos. Aliás, sendo o valor do indicador para os serviços veterinários igual a 65 (o quarto valor da tabela), é de presumir que também para qualidade de vida dos animais os produtos químicos sejam importantes! ${ }^{9}$

O ChemFactor foi calculado ao longo das cadeias de fornecimento de materiais para mais de 400 categorias de produtos industriais e de consumo. A análise global dos resultados mostrou que $96 \%$ dos bens fabricados "são tocados" directamente pela Indústria Química - a sua manufactura envolve o uso de produtos químicos; e que $6 \%$ do valor total dos produtos comprados pela economia provém da Indústria Química (excluindo as compras no interior da própria indústria). Definindo indústria dependente de produtos químicos como toda a indústria com ChemFactor igual ou superior a 10 (20 para as indústrias de serviços, que usam menos materiais), calculou-se ainda que a contribuição do conjunto destas indústrias para o PIB dos EUA correspondia a $25,2 \%$ deste.

\section{IMPORTÂNCIA DOS PRODUTOS QUÍMI- COS NO EMPREGO}

Um outro aspecto que interessa considerar para aferir a importância económico-social da Indústria Química é a sua contribuição para o emprego. $\mathrm{Na}$ Tabela 3 apresenta-se dados (EUA, 2004) ${ }^{10}$ [2] que permitem sentir a importância da Indústria Química como força motriz de criação de emprego. Aquela indústria era responsável por 882 mil postos de trabalho, mas envolvia directamente, a montante e a jusante, mais quase cinco milhões de empregos. O total de postos de trabaIho directamente ligados à Indústria Química, quase 5,8 milhões, correspondia a cerca de $4 \%$ da força de trabalho do país. Um cálculo simples a partir dos valores anteriores mostra que, por cada emprego na Indústria Química, se geram directamente 5,6 empregos na economia em globo ou seja, o factor multiplicativo ${ }^{11}$ do trabalho na Indústria Química é muito elevado, da ordem de 6,6 . Os $5,8 \mathrm{mi}-$ Ihões de postos de trabalho gerados a partir daquela indústria distribuem-se por sectores de actividade muito diversificados.
Tabela 2 Exemplos de valores dos índices ChemFactor*

\begin{tabular}{|c|c|}
\hline Actividade & Valor do índice \\
\hline \multicolumn{2}{|l|}{ 1.Produtos da actividade industrial e serviços } \\
\hline Tintas de impressão & 100 \\
\hline Serviços de design especializados & 48 \\
\hline Revestimento electrolítico & 42 \\
\hline Aglomerados de madeira & 31 \\
\hline Manufactura de sinais e tabuletas & 30 \\
\hline Semicondutores & 30 \\
\hline Fotocopiadores e equipamento fotográfico & 27 \\
\hline Botões & 26 \\
\hline Envelopes & 24 \\
\hline Fabrico de tijolos e telhas cerâmicas & 17 \\
\hline Extracção mineira de metais & 15 \\
\hline Tratamento de águas & 10 \\
\hline Computadores & 10 \\
\hline Aviões & 7 \\
\hline \multicolumn{2}{|l|}{ 2. Produtos de embalagem } \\
\hline Materiais plásticos para embalagem & 77 \\
\hline Garrafas de plástico & 74 \\
\hline Embalagens de papel forrado & 37 \\
\hline Caixas de cartão & 22 \\
\hline Embalagens de vidro & 17 \\
\hline Latas de metal & 7 \\
\hline \multicolumn{2}{|l|}{ 3. Bens de consumo } \\
\hline Tintas & 100 \\
\hline Laminados e revestimentos de vinilo (para o chão) & 77 \\
\hline Alcatifas e carpetes & 68 \\
\hline Serviços veterinários & 65 \\
\hline Pneus & 62 \\
\hline Artigos de cabeleireiro & 46 \\
\hline Serviços fotográficos & 45 \\
\hline Serviços hospitalares & 43 \\
\hline Brinquedos, bonecas e jogos & 38 \\
\hline Fraldas descartáveis & 37 \\
\hline CDs/DVDs/Cassetes de vídeo & 34 \\
\hline Artigos desportivos & 31 \\
\hline Pilhas & 37 \\
\hline Sapatos & 26 \\
\hline Livros & 25 \\
\hline Produtos para cirurgia & 25 \\
\hline Sofás e estofos & 24 \\
\hline Produtos de desenho, pintura, etc. & 23 \\
\hline Jornais e revistas & 21 \\
\hline Louças e talheres & 21 \\
\hline Lavandaria e limpeza a seco & 20 \\
\hline Mobílias de madeira & 17 \\
\hline Construção de casas & 15 \\
\hline Veículos a motor & 14 \\
\hline
\end{tabular}


Tabela 3 Dados sobre o emprego ligado directamente à Indústria Química (EUA, 2004)*

\begin{tabular}{|l|r|}
\hline \multicolumn{1}{|c|}{ Sector } & $\begin{array}{r}\text { Número de } \\
\text { postos de } \\
\text { trabalho } \\
\text { (milhares) }\end{array}$ \\
\hline Indústria Química & 882 \\
\hline Fornecedores & 676 \\
\hline Sectores a jusante & 4.226 \\
\hline Total & $\mathbf{5 . 7 8 4}$ \\
\hline $\begin{array}{l}\text { \% do Total de postos de trabalho } \\
\text { no país }\end{array}$ & $4 \%$ \\
\hline Factor multiplicativo & $\mathbf{6 , 6}$ \\
\hline *) Dados de [2]
\end{tabular}

O cálculo dos ChemFactors permitiu verificar que o alcance dos produtos químicos no mercado de emprego era muito mais amplo do que o evidenciado pelos valores da Tabela 3: as empresas com actividade dependente de produtos químicos empregavam 36 milhões de trabalhadores ou $26,1 \%$ da força de trabalho total dos EUA (ver na Tabela 4 a distribuição deste número pelas diversas actividades que manipulam produtos químicos). Se se comparar este número com os 882 milhares de trabalhadores da própria Indústria Química, obtém-se um "factor de toque" (dado pela razão dos dois valores) de quase 42 vezes. Considerando a soma dos números de trabalhadores na própria Indústria Química e nas indústrias dependentes, conclui-se que quase $27 \%$ do emprego nos EUA (2004) tinha alguma coisa a ver com produtos químicos. Esta percentagem é bem elucidativa da importância da Indústria Química para o emprego nos países industrializados.

\begin{tabular}{|c|c|}
\hline Sector de actividade & $\begin{array}{l}\text { Número de } \\
\text { empregos } \\
\text { (milhares) }\end{array}$ \\
\hline Indústria Química (emprego directo) & 882 \\
\hline Agricultura & 1.031 \\
\hline Indústria mineira e utilidades* & 404 \\
\hline Construção & 6.062 \\
\hline Fabrico de bens duráveis & 6.230 \\
\hline Fabrico de bens não duráveis & 3.669 \\
\hline Comércio grossista & 372 \\
\hline Informação & 1.299 \\
\hline Serviços & 4.877 \\
\hline Saúde & 12.055 \\
\hline Total & 35.998 \\
\hline (\% do Total de empregos no país & $26,1 \%)$ \\
\hline Total global & 36.880 \\
\hline (\% do Total de empregos no país & $26,6 \%)$ \\
\hline Factor de toque & 41,8 \\
\hline
\end{tabular}

QUANTIFICAÇÃO DA IMPORTÂNCIA DOS PRODUTOS QUÍMICOS NA QUALIDADE DE VIDA

Na Tabela 5 apresentam-se dados sobre valores da produção de produtos químicos no mundo, segundo o ACC [2]. Uma simples divisão do valor total pela população mundial [5] mostra que o valor médio da produção anual por habitante é superior a $\$ 350$ / pessoa / ano, mas este valor, como quase todas as médias, é enganador. Um relance à tabela evidencia que a produção ocorre maioritariamente na Europa $(36,9 \%)$ e América do Norte $(25,4 \%)$ e na Bacia do Pacífico $(28,4 \%)$, sendo que mais de dois terços deste último valor diz respeito ao Japão - ou seja, cerca de $80 \%$ dos produtos químicos são fabricados nos continentes ou países desenvolvidos e, naturalmente, beneficiam mais directamente os seus habitantes. estes usam presentemente o mesmo sistema estatístico, ${ }^{12}$ permitem analisar quantitativamente a importância dos produtos químicos para a maior ou menor qualidade média de vida dos respectivos habitantes - já que são todos países com grandes economias, embora com grau de desenvolvimento e nível de riqueza diferente. A partir dos valores da Tabela 5 e de dados sobre a população e Produto Interno Bruto (PIB) para os três países [5], pode-se calcular o valor de produção de produtos químicos por habitante para cada um dos países, verificando-se que esse valor cresce com o desenvolvimento económico, ocorrendo um fosso entre o México (\$184/habitante), país em desenvolvimento, e os outros dois, países afluentes (mais de \$1.000/habitante): México $\ll$ Canadá < EUA (ver a Fig. 1).

Para analisar melhor a relação, é útil

Tabela 5 A produção de produtos químicos no mundo (2004)*

\begin{tabular}{|c|c|c|}
\hline País/região & & $\%$ \\
\hline $\begin{array}{l}\text { EUA } \\
\text { Canadá } \\
\text { México }\end{array}$ & $\begin{array}{c}516 \\
36 \\
19\end{array}$ & $\begin{array}{c}23,0 \\
1,6 \\
0,8\end{array}$ \\
\hline Total parcial - América do Norte & 571 & 25,4 \\
\hline América Latina & 120 & 5,3 \\
\hline $\begin{array}{l}\text { Europa Ocidental } \\
\text { Europa Central e Oriental }\end{array}$ & $\begin{array}{c}748 \\
81\end{array}$ & $\begin{array}{c}33,3 \\
3,6\end{array}$ \\
\hline $\begin{array}{l}\text { Total parcial - Europa } \\
\text { África e Médio Oriente }\end{array}$ & $\begin{array}{c}829 \\
89\end{array}$ & $\begin{array}{c}36,9 \\
4,0\end{array}$ \\
\hline Ásia/Bacia do Pacífico & 637 & 28,4 \\
\hline Total - Mundo & 2246 & 100,0 \\
\hline
\end{tabular}

A maioria da população dos numerosos países pouco desenvolvidos da África e da Ásia, e mesmo dos países em desenvolvimento destes continentes e da América Latina, tem um acesso deficiente aos produtos químicos usados directamente (detergentes, remédios, fertilizantes, etc.) ou incorporados em bens - esta situação é análoga à da energia, podendo falarse, por semelhança, em pobreza química. A análise seguinte suporta este conceito.

Os valores apresentados para os três países da América do Norte, como representar o Produto Interno Bruto por habitante (PIB/hab) em função do valor de produtos químicos produzidos por habitante (ver a Fig. 2) - a representação mostra uma forte correlação entre as duas grandezas.

A Fig. 2 inclui um ponto referente ao Mundo, baseado no valor global da produção de químicos (Tabela 5) dividido pela população mundial e no PIB médio por habitante para o mundo, ponto esse que fica próximo do do México - denota valores baixos quer para a produção de químicos quer para a riqueza por habitante do pla- 
neta. Por outro lado, se se introduzirem naquela figura, como ordenadas, valores do $\mathrm{PIB} /$ habitante da ordem de $\$ 1.000 /$ pessoa, vulgares para os países pouco desenvolvidos [5], estimam-se valores irrisórios para o consumo de produtos químicos por habitante - o que evidencia a extensão do problema da pobreza química no mundo.
Na Fig. 3 apresenta-se as percentagens dos valores dos químicos produzidos relativamente ao PIB para cada um dos três países. A figura mostra que essa percentagem sobe pela ordem México < Canadá < EUA, isto é, sobe com o nível de desenvolvimento - pode-se, assim, concluir que o aumento da qualidade de vida

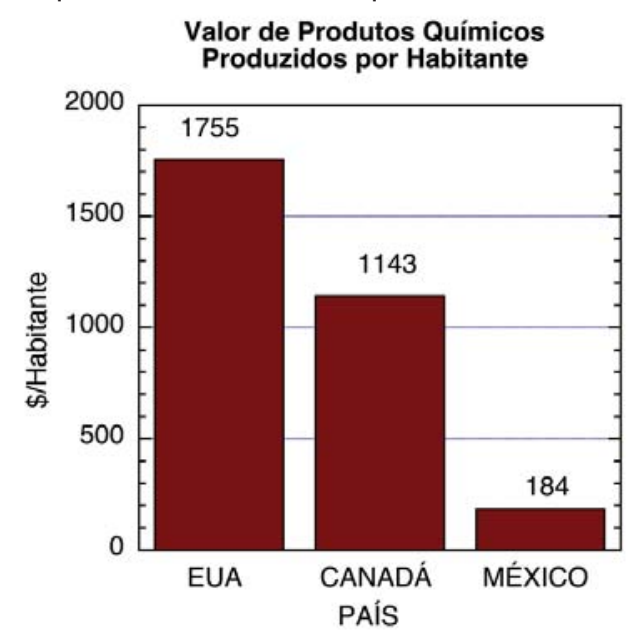

Figura 1 Produção de produtos químicos por habitante para os três países da América do Norte

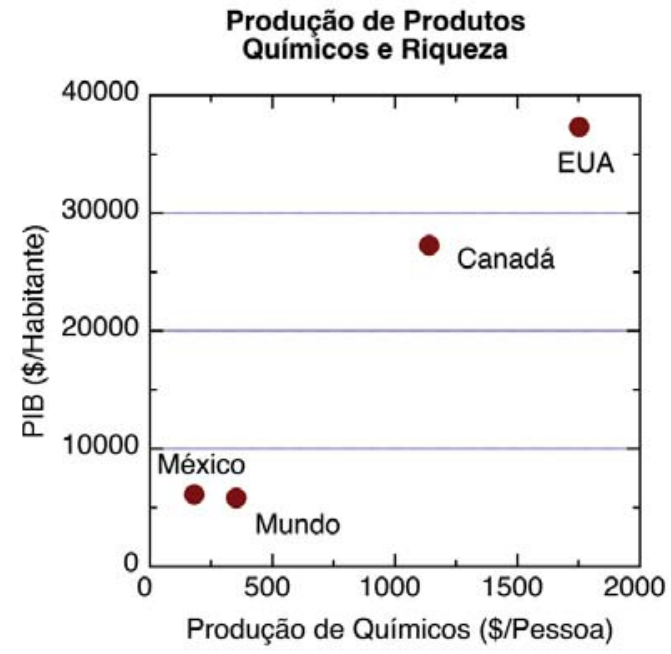

Figura 2 A qualidade de vida dos habitantes de um país, medida pelo PIB/habitante, apresenta uma forte correlação com valor de produtos químicos produzidos

\section{Valor do Fabrico de Produtos Químicos} na Economia Nacional



Figura 3 O valor dos produtos químicos fabricados cresce com a riqueza do país (medida pelo PIB/habitante)

está associado a uma maior quota de importância da Indústria Química na economia de um país. Note-se, ainda, que nos países avançados, como os EUA e o Canadá, a Indústria Química representa mais de $4 \%$ da economia (medida pelo PIB).

Em suma, embora os raciocínios anteriores envolvam incertezas decorrentes, por exemplo, de se ignorar as exportações e importações de químicos, os resultados obtidos mostram quanto a Indústria Química é um factor fulcral para obter riqueza e proporcionar qualidade de vida. Mais precisamente, usando o PIB por habitante como medida da qualidade de vida, conclui-se que quanto maior é o valor da produção de produtos químicos maior é a riqueza e a qualidade de vida que dela resulta.

A pobreza química, O DesenvolVIMENTO Sustentável e a Química VERDE

Uma prescrição do Desenvolvimento Sustentável, avançada logo no Relatório Brutland [6], é a diminuição do fosso da qualidade de vida entre os países pouco desenvolvidos e os afluentes - o que implicará melhorar a dos primeiros e, por isso, em face da discussão anterior, arrastará aumentos acentuados na quantidade de produtos químicos fabricados (e não só). Em consequência, o futuro da Indústria Química é promissor - é de prever que, em termos globais, tenha de continuar a crescer.

Por outro lado, o fabrico e uso de produtos químicos têm dado origem a enormes quantidades de resíduos e provocado a dispersão de variados poluentes, ocasionando problemas diversificados para a saúde humana e ecológica (para uma visão global, ver [7]), não admissíveis pelo Desenvolvimento Sustentável, e que não podem continuar a ocorrer. A pressão social e legislativa para a sua eliminação e atenuação tem vindo a crescer (por exemplo, na Europa, o REACH [8]), o que impõe que a química seja reformatada para que possa suportar a Sustentabilidade [9] - sendo assim inevitável o desenvolvimento progressivo da Química Verde e a intensificação do seu uso pela Indústria Quí- 
mica. Em suma, a pobreza química constitui, afinal, um poderoso estímulo para a mudança profunda no modo de praticar a química que a Química Verde constitui.

\section{Discussão finAl E CONCLUSÕES}

As estatísticas sobre a produção da Indústria Química dos países industrializados evidenciam quanto os produtos desta indústria contribuem para a qualidade de vida da sua população - não esquecendo, porém, que as estatísticas globais escondem o fosso entre ricos e os pobres: num mesmo país, como o nível de vida varia com os estratos populacionais, nem toda a gente beneficia igualmente com 0 fabrico e uso dos produtos químicos, aliás como sucede com todos os outros factores que determinam o nível de vida.

Os dados apresentados e a sua discussão demonstram a importância que a Indústria Química tem para a economia das sociedades industrializadas, algo de que os profissionais da Química Industrial têm plena consciência mas que o público em geral ignora - e mesmo alguns químicos académicos, por vezes, parecem esquecer. Em particular, os indicadores ChemFactor construídos por iniciativa do ACC revelam a penetração mais ou menos extensa dos produtos químicos na grande maioria das actividades económicas - indústria, serviços, consumo, etc. - dos países avançados, onde a civilização industrial atingiu um elevado nível de desenvolvimento.

Em face desta situação, o progressivo desaparecimento da Indústria Química no nosso país é um aspecto muito preocupante quanto ao modo como o desenvolvimento industrial tem sido implementado. Sendo aquela indústria extremamente importante como suporte de quase toda a actividade industrial e de serviços, bem como do emprego em geral, ${ }^{13}$ o seu esvaziamento implica consequências negativas de amplitude brutal para a actividade económica nacional, que transcendem em muito a própria Indústria Química. Como os produtos químicos são incorporados nos mais diversos bens de consumo, quer duradouros quer precários, a existência da indús- tria do seu fabrico contribui para um entrosamento denso e resiliente do tecido industrial, ao contrário de instalações pontuais de fábricas com outras actividades menos invasivas, isto é, cujos "factores de toque" são mais limitados (para já não mencionar que a instalação de tais fábricas por multinacionais é frequentemente temporária, ao passo que as grandes instalações da Indústria Química pesada, dados os vultuosos investimentos de capital que requerem, têm de ser construídas com um alcance temporal longo).

Por outro lado, em face do papel fulcral dos produtos químicos na civilização industrial é também preocupante o percurso que o ensino da química no Ensino Secundário tem vindo a seguir no nosso país, por exemplo: a progressiva diminuição do tempo lectivo dedicado à disciplina, que sugere uma tendência perigosa para o seu eventual banimento a curto prazo; ou a organização de programas tendo como base o difuso tema "moléculas no espaço", em vez da importância societal da química ou do valor económico da Indústria Química, temas potenciadores de um ensino da química dirigido ao papel dominante desta ciência no funcionamento da tecnosfera e na nossa vida diária - "moléculas na Terra"(!).

A análise apresentada mostra que há lugar para se falar de pobreza química, que tal como a pobreza energética, é uma componente da pobreza tecnológica, que, por sua vez, é uma das variadas facetas da pobreza em geral. Embora não seja possível apresentar dados que suportem a afirmação, dada a importância que a energia tem para a Indústria Química, é de presumir que as duas referidas pobrezas tecnológicas estejam fortemente correlacionadas. Outro aspecto a investigar será a correlação entre a diminuição da pobreza química e o crescimento da riqueza global (p. ex., $\mathrm{PIB} /$ habitante) ao longo do tempo, para as sociedades desenvolvidas ou em desenvolvimento. Em suma, a pobreza química parece ser um conceito suficientemente interessante para merecer estudos mais aprofundados.

Finalmente, em termos mais globais, a correlação existente entre a produ- ção de produtos químicos e a qualidade de vida significa que a melhoria das condições de vida nos países em desenvolvimento, e das populações menos favorecidas dos desenvolvidos, continuará a requerer um crescimento da referida produção. Este facto augura bom futuro à Indústria Química, desde que ela seja capaz de introduzir mudanças adequadas para que o fabrico e utilização dos seus produtos sejam feitos com menores danos para o ambiente e a saúde humana e ecológica - para o que tem de mudar a sua actividade para a rota do Desenvolvimento Sustentável. Neste contexto, a análise da importância económico-social da Indústria Química suporta, portanto, a premência de desenvolver a Química Verde e de concretizar a sua implementação por meio de Engenharia Química Verde, o mais rápida e extensivamente que for possível.

\section{Notas}

${ }^{1} \mathrm{O}$ conceito de pobreza energética ("energy poverty") aplica-se geralmente aos países menos desenvolvidos e países em desenvolvimento, onde se estima haver cerca de 2.000 milhões de pessoas, na maior parte rurais, sem acesso a serviços de fornecimento de combustíveis [1]. No entanto, o conceito também tem cabimento para os países desenvolvidos, onde se considera ocorrer ("fuel poverty") quando uma família tem de despender mais de $10 \%$ do rendimento disponível nas contas de electricidade, gás e outros combustíveis que consome (esta definição data dos fins dos anos oitenta do século passado, tendo sido introduzida por Boardman [10]). No Reino Unido, a erradicação deste problema foi contemplada por via legislativa (Warm Homes and Energy Conservation Act, 2000), mas o encarecimento dos custos de energia nos últimos anos tem-no acentuado [11]. Uma busca com o Yahoo (em 2009.06.06) conduziu a 399.000 páginas para "energy poverty" e 1.760 .000 para "fuel poverty", mas apenas a 57 para "chemicals poverty" (sem que nenhuma destas últimas se referisse ao conceito tal como formatado no presente artigo). Uma busca na Wikipedia (em 2009.06.06) mostrou que esta não continha a entrada "chemicals poverty", ao contrário das 
duas referentes à pobreza energética.

2 O autor deste artigo tem usado, na cadeira sobre Química Industrial que vem leccionando desde meados dos anos oitenta do século passado, dados estatísticos sobre a Indústria Química dos EUA e sua produção, como exemplo da situação dos países avançados quanto ao fabrico e uso dos produtos químicos. Como se trata de um grande país, com uma Indústria Química muito diversificada, os dados estatísticos, relativamente fáceis de obter e uniformes, evidenciam muitos aspectos importantes daquela indústria. Entretanto, com o desenvolvimento do resto do mundo, particularmente dos países da Bacia do Pacífico (mas não só), e mais recentemente, com o avanço da Globalização, a importância económica dos EUA e da sua Indústria Química tem-se vindo a esbater - nos meados dos anos oitenta a economia dos EUA representava cerca de um terço da economia mundial, presentemente já representa menos de um quarto. Em 2007, a Indústria Química dos EUA produziu $21 \%$ dos produtos químicos fabricados no mundo [2].

3 Um componente virtual dum produto é algo que, não existindo fisicamente no produto, foi utilizado no seu fabrico ou obtenção, por exemplo, o conteúdo virtual de água em $1 \mathrm{~kg}$ de cereal é de $1.000 \mathrm{~L}$.

${ }^{4}$ Ou "fórmulas" - misturas de compostos que, além do composto funcional para a utilização, incluem outros, destinados a potenciar a actividade dele, estabilizá-lo, etc.

${ }^{5}$ Por exemplo, em 2007, um automóvel fabricado nos EUA incorporou, em média, $\$ 2.664$ de produtos químicos, mais de $10 \%$ do seu custo de fabrico - produtos químicos reais (por exemplo, plásticos, espumas, borrachas, etc.) ou virtuais (por exemplo, ácido sulfúrico usado no fabrico do aço) [12].

${ }^{6}$ Em rigor, como a Lua já foi visitada por humanos e foi enviado para lá variado equipamento de observação, apesar das precauções tomadas para não deixar lixo, não se pode garantir que não existam lá resíduos de químicos artificiais!

7 Tradução literal de "touch indicator".

${ }^{8}$ Os valores da tabela são os referentes a 2004, ano em que os indicadores ChemFactor começaram a ser obtidos pelo ACC [4]. Valores aparentemente mais recentes, embora menos completos, podem ser obtidos na respectiva página [2] (as diferenças nos valores são pequenas).

9 Não se pode esquecer, porém, que a quase totalidade dos animais são hoje criados para acabarem no prato dos humanos!

10 Neste artigo, usaram-se dados de fabrico de produtos químicos, emprego, etc., referentes a 2004 por duas razões: por um lado, os valores dos ChemFactor foram obtidos para este ano; por outro, naquele ano, após a crise do início da década e antes do encarecimento do petróleo que ocorreu mais recentemente, a economia atravessava um período de relativa estabilidade.

11 O factor multiplicativo é a razão entre o número de postos de trabalho totais e o número de postos de trabalho na Indústria Química.

12 Os três grandes países da América do Norte (Canadá, EUA e México) adoptaram, em 1997, no âmbito do acordo comercial NAFTA ("North America Free Trade Agreement"), um sistema estatístico de actividades económicas uniformizado, conhecido pela sigla NAICS ("North American Industry Classification System"), pelo que as comparações dos dados estatísticos para os três países são fidedignas, pelo menos em princípio.

${ }^{13}$ Para já não falar do emprego profissional dos químicos.

\section{REFERÊNCIAS}

[1] A. D. Sagar, "Alleviating Energy Poverty for the World's Poor", En. Pol. 33 (2005) 1367-1372.

[2] American Chemistry Council (ACC), em http://www. americanchemistry.com/s_ acc/index.asp.

[3] P. R. Seidl, M. N. Magalhães e C. R. Augusto, "An Introductory Course in Industrial Chemistry for Freshman", J. Chem. Ed. 78 (2001) 218-222.

[4] M. G. Moore e T. K. Swift, "Driving the Economy", American Chemistry (2005) 24-26 de Setembro.

[5] The Economist, "Pocket World in Figures", 2006.

[6] G. H. Brutland (Chairwoman), "The World Commission on Environment and Development", Our Common Future, Oxford UP, 1987.

[7] OECD Environmental Outlook to 20030 , OCDE, 2008

[8] Royal Society of Chemistry, A Brief Guide to Reach, RSC, 2008.

[9] A. A. S. C. Machado, "Química e Desenvolvimento Sustentável - QV, QUIVES, QUISUS", Química - Boletim SPQ 95 (2004) 59-67.

[10] B. Bordman, Fuel Poverty: From Cold Homes to Affordable Warmth, Wiley, 1991.

[11] T. Webb, "Fury as Fuel Poverty Soars Close to a 10-Year Record", The Observer (2008) 20 de Janeiro.

[12] A. Tullo, "Impact of GM's Bankruptcy", Chem. Eng. News 87(23) (2009) 8 de Junho, 8 .

\section{Actualidades Científicas}

\section{Reservas naturais de fosfatos em PERIGO DE EXAUSTÃo?}

Os fertilizantes à base de fosfatos ajudaram o forte aumento da produtividade agrícola verificado no século passado, mas discute-se se corremos o risco de, num futuro próximo, esgotar-mos as reservas disponíveis. Tal como a discussão em torno das reservas de petróleo, pode dar-se o caso de haver uma contínua descoberta de novas reservas (embora com custos crescentes de exploração e/ou purificação), mas não podemos esquecer que todas elas são limitadas e as nossas necessidades não param de crescer a ritmos impressionantes.

Num artigo publicado na revista Nature do passado dia 8 de Outubro, Natasha Gilbert procura esclarecer se há ou não razões para alarme.

Embora as estimativas que se fazem do consumo e das reservas existentes estejam sujeitas a erros não quantificáveis, inerentes à falta de informação (intencional ou não, por exemplo no que respeita a estratégias de concorrência e de constituição de reservas estratégicas), vale a pena apresentar e pensar nos números que se conse- 
guem apurar. Estima-se que em 2008 tenham sido extraídas 161 milhões de toneladas de fosfato. Admite-se que haverá um crescimento na procura de fertilizantes de 2,5 a $3 \%$ ao ano nos próximos 5 anos.

Por outro lado, estima-se que as reservas de fosfato no solo restantes (concentradas essencialmente em Marrocos, Saara Ocidental, China, Estados Unidos, Rússia e África do Sul) sejam de 62 mil milhões de toneladas (ou seja, 62 gigatoneladas). Tomando como base estes valores, prevê-se que as reservas se esgotem em cerca de 125 anos. Contudo, o facto de a população mundial estar a crescer rapidamente pode reduzir esta previ- são, havendo quem aponte um limite temporal de 50 anos!

Porém, a elevada incerteza nos valores das reservas pode tornar este cenário menos preocupante. De qualquer forma, há quem peça a criação de uma entidade internacional que, à semelhança do que se passa para a água, energia ou azoto, assuma a responsabilidade dos recursos de fosfato.

Os agricultores têm usado os fertilizantes em excesso por precaução. Se tal procedimento inflacciona as necessidades e impulsiona a procura, a verdade é que ele cria reservas de fosfatos no solo. Os agricultores na
Europa e nos Estados Unidos têm vindo a reduzir a sua utilização, mas na China a utilização excessiva é ainda um facto.

Os mais optimistas argumentam que haverá outras fontes ainda não descobertas, embora não se consiga prever o seu impacto.

A verdade é que actualmente não há um substituto para o fosfato pelo que, mesmo nos cenários mais optimistas, não podemos deixar de colocar (também) este recurso sob vigilância.

JM

\section{VIDA EXTRA-TERRESTRE EXÓTICA ? À PROCURA DE FORMAS DE VIDA DESCONHECIDAS.}

Foi criado na Universidade de Viena um grupo de investigação de "Solventes Alternativos como base para Zonas de Suporte de Vida em Sistemas (Exo-) Planetários" liderado pela Prof ${ }^{a}$ Maria Firneis.

Estes cientistas procuram estudar como pode ocorrer a evolução de vida em solventes "exóticos", como ácido sulfúrico em vez de água, envolvendo bioquímica exótica.

Tradicionalmente, procuram-se planetas que possam sustentar vida em "zonas habitáveis", ou seja, em regiões em torno de estrelas nas quais existam planetas do tipo Terra que possuam atmosferas com dióxido de carbono, vapor de água e azoto e que possam ter água líquida à sua superfície.

Os cientistas têm procurado biomarcadores produzidos por vida extraterrestre com metabolismos semeIhantes aos terrestres, em que a água é utilizada como solvente e em que as "peças de lego" da vida são aminoácidos, baseados em carbono e oxigénio. Contudo, estas podem não ser as únicas condições em que se desenvolve vida. Aliás, na Terra, há ecossistemas "extremos" que seriam inviáveis para os seres vivos terrestres comuns mas que, mesmo assim, suportam organismos.

Parece ser a altura de adoptar uma atitude mais radical e admitir que possam existir outras formas de vida diferentes das terrestres, que não dependem de água, nem de metabolismos baseados no carbono ou oxigénio.

Um dos requisitos de um solvente que possa suportar vida é que se mantenha líquido num amplo intervalo de temperaturas. A água é líquida entre $0{ }^{\circ} \mathrm{C}$ e $100{ }^{\circ} \mathrm{C}$, mas outros solventes permanecem líquidos a temperatura superiores a $200{ }^{\circ} \mathrm{C}$. Tais líquidos podem permitir a existência de um oceano num planeta próximo da estrela central.

No extremo oposto, um oceano de amónia pode existir a distâncias à estrela central superiores.

Além disso, pode encontrar-se ácido sulfúrico na atmosfera de Vénus e sabemos ainda que há lagos de metano/ etano que cobrem parte da superfície de Titã, a maior lua de Saturno.

Não admira pois que se mantenha acesa a discussão sobre a existência de vida extra-terrestre e sobre quais as melhores estratégias para a sua detecção, e não apenas nos exoplanetas e zonas habitáveis.
É objectivo deste grupo vienense, e dos seus colaboradores internacionais, investigar as propriedades de uma gama de solventes (excluindo a água), incluindo a sua abundância no espaço, as suas características térmicas e bioquímicas bem como a sua capacidade de suportar a origem e a evolução de metabolismos que suportem vida (ver www.europlanet-eu.org/ demo/). 